\title{
Analysis of the Reinforced Retaining Wall Seismic Dynamic Response and its Ground Motion Parameter Tensor
}

\author{
Yang Junchao $^{1}$, Li Lihua ${ }^{1}$, Xiao Henglin ${ }^{1}$,He Zhirong ${ }^{2}$ and Yang Zhiyong ${ }^{1}$ \\ ${ }^{1}$ School of Civil Engineering and Architecture, Hubei University of Technology, Wuhan 430068, \\ China; \\ ${ }^{2}$ School of civil engineering and architecture, Wuhan University of Technology, Wuhan, 430070, \\ China
}

Keywords: Reinforced retaining wall, Seismic response, Tensor analysis, Time history response, Tension peak.

\begin{abstract}
In order to improve the accuracy of reinforced retaining wall seismic dynamic response analysis, this paper presents a response model seismic based on dynamic parameter tensor analysis, and inversion calculation can obtain the time history response curve and the maximum peak force of the reinforced retaining wall. In order to verify the validity and reliability of the model, the model is programmed using MATLAB software, the stability data of reinforced earth retaining wall are obtained by iterative calculation, and then the use of ADINA software establishes the finite element model of reinforced retaining wall, and finally we obtain the maximum tension distribution of the reinforced retaining wall. A comparative analysis of MATLAB and ADINA results found that their error is within $5 \%$, software calculation results are very close to model calculation results, so as to verify the reliability of tensor model in reinforced retaining wall seismic analysis, they can be popularized in the seismic dynamic response analysis.
\end{abstract}

\section{Introduction}

Reinforced retaining wall is a new type of supporting structure, it has beautiful appearance and low cost, so it is widely used in transportation and urban construction [1,2]. Through a lot of experiments and practice, they prove that the seismic performance of reinforced earth retaining wall is very good, but, it is necessary to design a reasonable design in order to still show good performance in strong earthquake [3-5]. However, the design of retaining wall is still in the exploration stage, theory lags behind practice, so the theoretical analysis of the retaining wall under the strong earthquake is very important. The main purpose of this study is to analyze the dynamic response of reinforced retaining wall under the seismic action, and this paper puts forward a new seismic analysis tensor model, making the reinforced retaining wall design more reasonable.

\section{The Structural Characteristics of Reinforced Retaining Wall}

Reinforced retaining wall mainly consists of four parts, including reinforced materials, soil, foundation and panel, in which the role of the panel is mainly barrier behind the wall backfill, the material mainly has reinforced concrete, stone, metal products etc. [6-8]. In China, we mainly use the reinforced concrete and concrete panel, the structure diagram of reinforced retaining wall is shown in Figure 1.

Figure 1 shows a schematic diagram of the reinforced retaining wall, its structure includes reinforcing soil, reinforcing bar, panel and foundation. The function and the panel of the reinforced soil body are integrated with the panel to resist the fill pressure and load resistance, so as to make the soil more stable. Using the adhesive force and friction force of clay, the band forms complex with surrounding soil, when the soil deformation occurs, band will pass through the tension to carry on soil reinforcement, so that the wall will not collapse, strengthening the stability of the wall. 


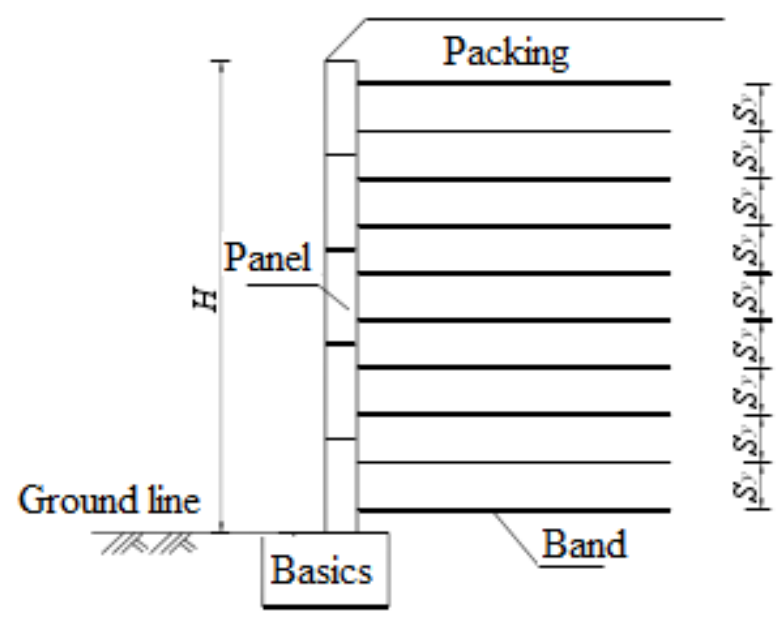

Fig. 1 Schematic diagram of reinforced retaining wall

\section{The Seismic Response Tensor Model of Reinforced Retaining Wall}

In order to make the reinforced retaining wall seismic dynamic response characteristic analysis closer to reality, this paper chooses the longer period and better effect low-frequency response data in the main shock tensor inversion [9-11]. Due to the different seismic frequency components and source, we use different parameters in each seismic waves processing, the specific parameters are shown in Table 1.

Table 1. Seismic data processing

\begin{tabular}{|c|c|c|c|c|c|c|}
\hline $\begin{array}{c}\text { Recording } \\
\text { time }\end{array}$ & $\begin{array}{c}\text { Incident angle/ } \\
\text { Degree }\end{array}$ & $\begin{array}{c}\text { Refraction } \\
\text { angle/ Degree }\end{array}$ & $\begin{array}{c}\text { Acceleration } \\
/ \mathrm{m} / \mathrm{s}^{2}\end{array}$ & $\begin{array}{c}\text { Sampling } \\
\text { frequency /Hz }\end{array}$ & $\begin{array}{c}\text { Data length } \\
/ \mathrm{s}\end{array}$ & Units \\
\hline 1 & 102.22 & 31.32 & 8.2 & 6 & 35 & 15 \\
\hline 2 & 101.23 & 31.33 & 7.3 & 6 & 37 & 17 \\
\hline 3 & 103.25 & 32.66 & 6.5 & 6 & 32 & 15 \\
\hline 4 & 101.58 & 31.25 & 6.8 & 6 & 36 & 16 \\
\hline 5 & 102.63 & 31.39 & 6.7 & 6 & 33 & 18 \\
\hline 6 & 102.66 & 32.28 & 5.3 & 6 & 38 & 13 \\
\hline 7 & 102.35 & 32.23 & 6.6 & 6 & 35 & 18 \\
\hline 8 & 103.48 & 31.88 & 8.8 & 6 & 38 & 16 \\
\hline
\end{tabular}

Table 1 indicates that in the different time and location, the use of different frequency, data length and seismic units collect the seismic processing data, its parameters include incident angle, refraction angle and acceleration. In the case of earthquake point source approximation, ground motion induced by the earthquake is shown

$$
U_{i}(r, t)=\sum_{k=1}^{8} G_{i k}\left(r, t ; r_{s}\right) * M_{k}(t)
$$

In which, $U_{i}(r, t)$ represents the $i$-th recorded data of the seismic phase, $r$ indicates the seismic station location, $r_{s}$ indicates the source location, $G_{i k}\left(r, t ; r_{s}\right)$ represents the $k$-th component corresponding to the Green function in $i$-th recorded data, and $M_{K}(t)$ represents the component of the moment tensor. In theory, the seismic moment tensor can be obtained directly by the reinforced retaining wall. However, because of the large number of parameters as well as the error of the Green function and observation data, the inversion results are often unstable, so it is needed to reduce the number of unknown variables. Assuming that each component of the moment tensor has the same time history, the constraints of each element are calculated by iteration, and then we can obtain the same time traversal moment tensor. The steps are as follows [12]: 
(1) The time traversal of 8 moment tensor components $s_{k}(t) k=1,2, \ldots, 8$ and the amount of the moment tensor $M_{o k}$ are separated, its expression is

$$
M_{k}^{(n)}(t)=\frac{\int M_{k}{ }^{(n)}(t) d t}{\left|\int M_{k}{ }^{(n)}(t) d t\right|} M_{o k}{ }^{(n)} s_{k}{ }^{(n)}(t)
$$

Among them, $n$ represents the number of iterations.

(2) The time traversal of 6 moment tensor components constructs the same time traversal.

$$
s^{(n)}(t)=\frac{\sum\left(M_{k}{ }^{(n)}\right)^{2}\left(\left|s^{(n)}(t)\right|+s^{(n)}(t)\right) / 2}{\sum\left(M_{k}{ }^{(n)}\right)^{2}} M_{o k}{ }^{(n)} s_{k}{ }^{(n)}(t)
$$

Among them, $s^{(n)}(t)$ represents the $n$-th iteration source calculation with the time function $s(t)$.

(3) The same time traversal is given the six component of the seismic moment tensor.

$$
M_{k}{ }^{(n+1)}(t)=\frac{\int M_{k}{ }^{(n)}(t) d t}{\left|\int M_{k}{ }^{(n)}(t) d t\right|} M_{o k}^{\left({ }^{(n)}\right.} s_{k}^{(n)}(t)
$$

Using the above process, we can get the source function $s(t)$, and the expression of the ground motion caused by the earthquake can be written

$$
U_{i}(r, t)=\sum_{k=1}^{8}\left(G_{i k}\left(r, t ; r_{s}\right) * s(t)\right) * M_{k}
$$

In formula (5), it can be seen that solved unknowns is only six component amplitude of the moment tensor $M_{K}$, and then we can obtain the moment tensor solution of reinforced retaining wall seismic dynamic response.

\section{Analysis of Reinforced Retaining Wall Seismic Action Characteristics}

In order to verify the validity of the seismic response tensor model, this paper uses the seismic action characteristic of the reinforced retaining wall, to carry on analogue simulation and analyze the reliability of the model $[13,14]$. The numerical simulation selects the sinusoidal seismic wave, earthquake excellence cycle is 0.5 , the magnitude is 7 , the damping ratio of the soil is $15 \%$, the shear modulus is $7 \mathrm{MPa}$, and the elastic modulus is $25 \mathrm{Mpa}$ [15]. Based on the above parameters, this paper uses the MATLAB software to program the tensor model of seismic response, and then time range analysis results of tensile force as shown in Figure 2 can be obtained by iterative calculation.

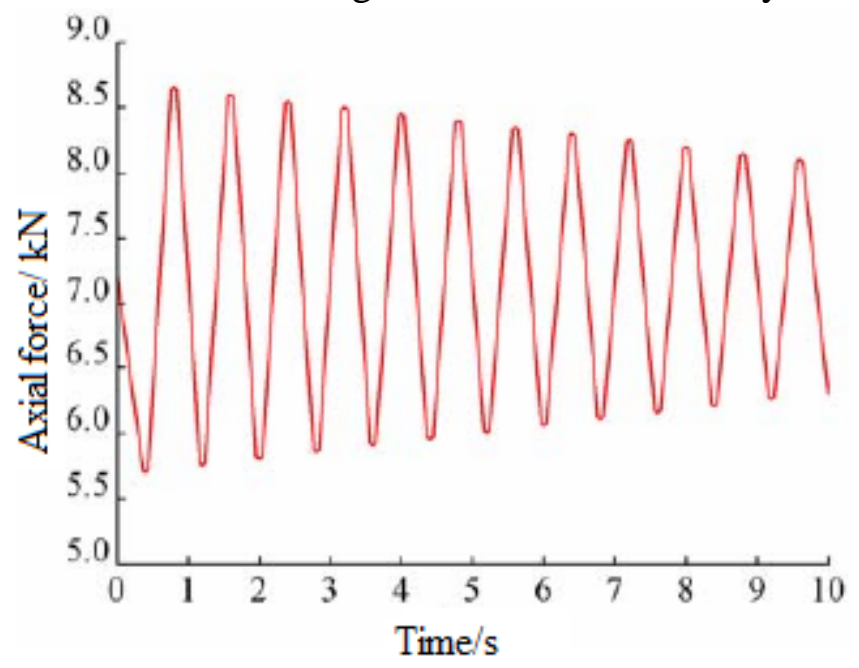

Fig. 2 The time course curve of tensile force 
Figure 2 shows the time course curve of tensile force obtained by MATLAB numerical simulation, it can be seen that, the maximum tensile strength reached $8.66 \mathrm{kN}$ under the earthquake response, the band do periodic reciprocating motion under the seismic wave action, and band is gradually attenuated under the action of damping.

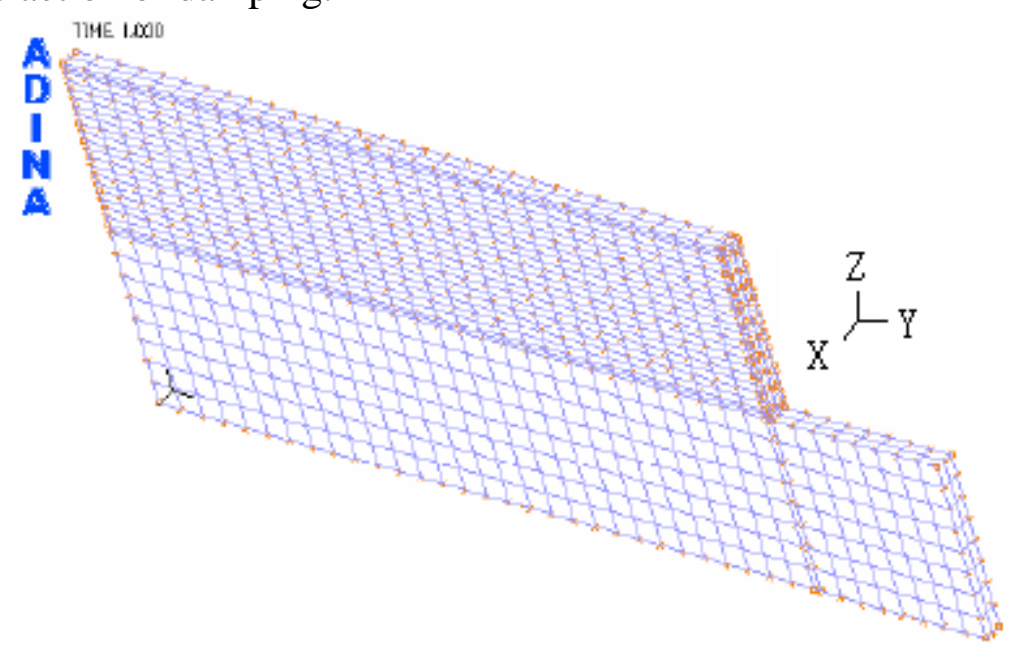

Fig. 3 ADINA finite element model

Figure 3 represents the ADINA finite element model. First of all, this model carries out the static analysis, and then applying the seismic response carries out seismic dynamics analysis. The soil and wall panels use the 8 node three-dimensional solid element, the material is elastic material, the reinforced uses rebar unit, the wall panels of reinforced retaining wall and soil uses the contact element, the maximum pulling force of each layer can be obtained by input seismic time function and iterative computation, its calculation results are shown in Figure 4.

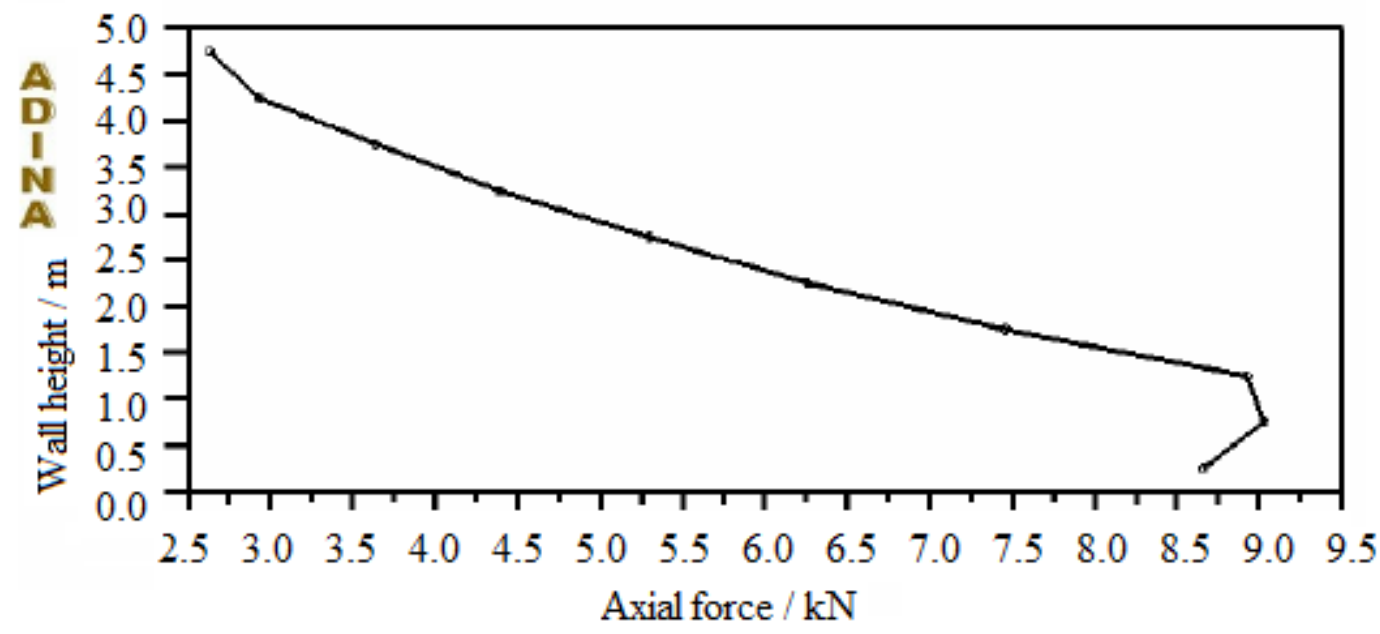

Fig. 4 The maximum tension distribution of the reinforced retaining wall

Figure 4 shows the maximum tension distribution results of the reinforced retaining wall. By comparison with Figure 2, we can see that the maximum band tension is close to the peak value of the seismic action, and their error is less than $5 \%$, the results show that the tensor matrix calculation results are consistent with ADINA software calculation results, so as to verify the reliability of ground motion parameters tensor analysis model. Therefore, the model can be used in the seismic dynamic response analysis of reinforced retaining wall.

\section{Summary}

In order to improve the accuracy of reinforced retaining wall seismic dynamic response characteristics, this paper establishes the ground motion parameter tensor model of reinforced retaining wall, the use of MATLAB software carries out programming design for the seismic response tensor model, and then response curves of reinforcement tensile force and the maximum 
tension peak can be obtained by calculating. The finite element model of reinforced retaining wall is established by ADINA software, the maximum tension distribution of reinforced retaining wall is obtained by calculating, and compared with the results of tensor model analysis, the results show that the error is less than $5 \%$, software calculation results are close to model calculation, so as to verify the validity and reliability of the tensor analysis model.

\section{References}

[1] L.P. Ye, Z. Qu, X.Z. Lu, P. Feng. The design idea and method of improving the building structures anti seismic collapse capacity. Journal of building structures, 2014, 29(4): 50-42.

[2] X. Guo. New understanding of earthquake damage and anti collapse in Wenchuan earthquake. Eighth session national earthquake engineering academic conference, 2013: 291-297.

[3] X. Guo. Analysis of earthquake damage characteristics and its causes in Wenchuan earthquake. Earthquake engineering and engineering vibration, 2014, 28(3): 74-87.

[4] X.F. Jiang, Y.Y. Chen. Research status of building structural progressive collapse and control design. Journal of civil engineering, 2013, 41(6): 1-8.

[5] B.X. Li, H.P. Xie, J.H. Deng. Thinking of buildings seismic design and its seismic characteristics in Wenchuan earthquake. Journal of disaster prevention and Mitigation Engineering, 2013, 29(2): 224-236.

[6] X.Y. Quan, W. Mi, Z.Q. Zhang. Stair structure broken ring phenomenon and its countermeasures in Wenchuan earthquake. Building structure, 2013, 39(11): 75-77.

[7] X.B. Hu, J.R. Qian. Monolayer plane steel frame progressive collapse dynamic effect analysis. Engineering mechanics, 2013, 25(6): 38-43.

[8] S.N. Huang. The seismic problem of village buildings in Yushu earthquake damage. World earthquake engineering, 2014, 27(2): 191-196.

[9] L.K. Yao, D.F. Jun, M. Yang. The inspiration of subgrade disaster analysis and its seismic code improvement in Wenchuan earthquake. Journal of Southwest Jiaotong University, 2013, 44(3): 302-311.

[10] G.W. Cheng, X.S. Zhao, L. Li. Analysis of the seismic stability of reinforced slope based on pseudo static method. Journal of Yangtze University, 2014, 6(4): 295-297.

[11] L.H. Zhao, L. Li, F. Yang. The quasi - static analysis of reinforced slope dynamic stability. Chinese Journal of rock mechanics and engineering, 2014, 28(9): 1904-1917.

[12] J.Q. Jiang, G.L. Yang. Analysis of the seismic stability of reinforced earth retaining wall. China Railway Science, 2013, 30(1): 36-40.

[13] Y.S. Zou, J.Q. Jiang. Analysis of the internal stability of reinforced retaining wall under the complex dynamic action. Central South Highway Engineering, 2013, 32(1): 51-54.

[14] Y.X. Yin, X.H. Yang. The numerical simulation of reinforced retaining wall under the dynamic action. Journal of Henan University Of Urban Construction, 2013, 16(1): 56-58.

[15] Y.S. Zou, J.Q. Jiang. Analysis of Numerical simulation of reinforced retaining wall under the dynamic action. Journal of Hunan City University, 2014,15(4): 12-14. 